\title{
Do randomized clinical trials always provide certain results? \\ The case of tralokinumab in idiopathic pulmonary fibrosis
}

\author{
Mark G. Jones ${ }^{1}$, Giacomo Sgalla ${ }^{2}$, Luca Richeldi ${ }^{1,2}$ \\ ${ }^{1}$ National Institute for Health Research Southampton Respiratory Biomedical Research Unit \\ and Clinical and Experimental Sciences, University of Southampton, Southampton, UK; \\ ${ }^{2}$ Division of Respiratory Medicine, Università Cattolica del Sacro Cuore, Fondazione \\ Policlinico “A. Gemelli”, Rome, Italy
}

Correspondence to:

Professor Luca Richeldi

Unità Operativa Complessa di Pneumologia

Università Cattolica del Sacro Cuore

Fondazione Policlinico A. Gemelli

Rome 00168

Italy

E-mail: luca.richeldi@unicatt.it

Word count 962 (excluding references) 
Randomized controlled trials (RCTs) are typically considered the reference standard when regulators and clinicians evaluate the benefits and risks of a proposed therapy. Any limitations in RCT design and execution will compromise the interpretation and applicability of study outcomes. When RCTs are designed, significant emphasis is therefore placed upon ensuring validity both internally (i.e. eliminate possible biases) and externally (i.e. assure clinical relevance) (1). Given the prolonged period from conception to commencement to completion of trials, there is a risk that the diagnostic and therapeutic standards of care may alter, so influencing patient recruitment, selection, retention, and ultimately interpretation and applicability of results. Recently, this may perhaps be best illustrated by idiopathic pulmonary fibrosis (IPF), where the approval of two anti-fibrotic therapies over the past 5 years has transformed patient care and so the design and execution of RCTs (2).

Parker and colleagues report the findings of a phase 2 RCT evaluating the safety and the efficacy of tralokinumab, an IL-13 monoclonal antibody, in subjects with mild to moderate IPF (5). Patients were randomized 1:1:1 to receive placebo or tralokinumab 400 mg or 800 mg every 4 weeks for 68 weeks. The primary efficacy endpoint was absolute change in \% predicted forced vital capacity (FVC) from baseline to week 52 in an intentionto-treat population. In an attempt to a commendable "stratified medicine" approach, the matricellular protein periostin, a putative biomarker for the IL-13 axis, was measured to stratify periostin-high and periostin-low subgroups. Unfortunately, following a pre-defined interim analysis identifying lack of efficacy, the dosing of the study drug has been discontinued.

This was a well-designed RCT with a clear underlying scientific rationale, however interpretation of the apparently negative findings must be considered in the context of the trial design during the rapidly changing landscape of IPF in which it was conducted. During 
this period, many challenges were encountered by this trial, thus highlighting issues of relevance to current and future studies of putative IPF therapies.

When selecting RCT eligibility criteria, generalisability to the population of patients with a disease must be balanced with a wish to ensure homogeneity of the trial population and so increase the probability of an efficacy signal. In this study, a definite diagnosis of IPF confirmed by an independent review of imaging and mild to moderate functional impairment at baseline (FVC $\geq 50 \%$ predicted) were both required for inclusion. Almost sixty percent of patients failed screening, and the Authors discuss that this may limit application of these findings to a real-world population. This screen failure rate was similar to the ASCEND trial, where $65 \%$ of patients were excluded (4). In contrast, the INPULSIS trials reported $28 \%$ of patients failing screening, likely due to the application of less strict diagnostic criteria and the use of a single central reader for chest imaging (3). Whilst current guidelines require the presence of honeycombing for a definite radiological diagnosis of IPF, in the INPULSIS trials IPF was diagnosed radiologically if either honeycomb lung destruction or traction bronchiectasis and a reticular abnormality consistent with fibrosis were present in a basal and peripheral predominance. Pre-defined subgroup analysis of the INPULSIS population showed similar functional decline and response to treatment between groups of participants with or without evidence of honeycombing at HRCT (6), suggesting that broader criteria might at the same time lower screen failure rates and ensure greater generalizability of findings without affecting study uniformity.

Patient retention is a key factor if RCTs are to minimize bias and variability (7). In the Parker trial, between recruitment commencement in October 2012 and interim analysis in August 2015, efficacy of nintedanib and pirfenidone was demonstrated in phase 3 trials (3, 4, 8). As the design of the study excluded patients on nintedanib or pirfenidone, it is 
perhaps not surprising that at the interim 52-week analysis upon which the decision was made to discontinue the trial for lack of efficacy, only $103(58 \%)$ subjects remained in the study, with $>20 \%$ patients having withdrawn consent. Ultimately, only 43 (24\%) subjects completed the study. Such significant discontinuation rates severely limit study interpretation, and highlights that the introduction of pirfenidone and nintedanib has heralded the end of long-term placebo-controlled RCTs. Whilst short term Phase 1 or Phase 2a trials investigating safety or proof of target engagement might still be feasible with careful design, longer term safety and efficacy RCTs will require add on to current standard of care or risk very limited patient recruitment and an atypical population. In this context, combination therapy is likely to be the future standard of care in IPF, as in many other respiratory disorders (9). An additional challenge with such add on trials will be the anticipated slower rate of decline in disease progression and so careful protocol design will be required to achieve efficacy signals, including the adoption of cohort enrichment strategies and more flexible composite endpoints (10).

Finally, what biological insights into the role of the IL-13 axis in IPF has this study provided? The authors propose that the study demonstrates blockade of IL-13 alone is insufficient to impact the progression of mild to moderate IPF, and that serum periostin has limited utility as a predictive biomarker. Given the complex pathogenesis of IPF it is perhaps not unexpected to identify that IL-13 is not a core pathway of fibrosis and to propose that modulating multiple pathophysiological fibrotic pathway may be required for treatment success, however this conclusion must be considered within the context of an RCT with a very high screen-failure rate, the biased inclusion of a potentially atypical population of patients, a high discontinuation rate, and early study termination. Findings from an ongoing study of the anti-IL-13 agent lebrikizumab (NCT01872689) are awaited which will further 
inform any role for therapeutic targeting of IL-13 in IPF.

\section{REFERENCES}

1. Rothwell PM. Factors that can affect the external validity of randomised controlled trials. PLoS clinical trials 2006;doi:10.1371/journal.pctr.0010009

2. Richeldi L, Collard HR, Jones MG. Idiopathic pulmonary brosis. The Lancet 2017;389:1941-1952.

3. Richeldi L, Bois du RM, Raghu G, Azuma A, Brown KK, Costabel U, Cottin V, Flaherty KR, Hansell DM, Inoue Y, Kim DS, Kolb M, Nicholson AG, Noble PW, Selman M, Taniguchi H, Brun M, Le Maulf F, Girard M, Stowasser S, SchlenkerHerceg R, Disse B, Collard HR. Efficacy and Safety of Nintedanib in Idiopathic Pulmonary Fibrosis. N Engl J Med 2014;370:2071-2082.

4. King TE Jr., Bradford WZ, Castro-Bernardini S, Fagan EA, Glaspole I, Glassberg MK, Gorina E, Hopkins PM, Kardatzke D, Lancaster L, Lederer DJ, Nathan SD, Pereira CA, Sahn SA, Sussman R, Swigris JJ, Noble PW. A Phase 3 Trial of Pirfenidone in Patients with Idiopathic Pulmonary Fibrosis. N Engl J Med 2014;370:2083-2092.

5. Parker JM, Glaspole IN, Lancaster LH, Haddad TJ, She D, Roseti SL, Fiening JP, Grant EP, Kell CM, Flaherty KR. A Phase 2 Randomized Controlled Study of Tralokinumab in Subjects with Idiopathic Pulmonary Fibrosis. Am J Respir Crit Care Med [online ahead of print] 08 Aug 2017;

www.atsjournals.org/doi/abs/10.1164/rccm.201704-07840C

6. Raghu G, Wells AU, Nicholson AG, Richeldi L, Flaherty KR, Le Maulf F, Stowasser S, Schlenker-Herceg R, Hansell DM. Effect of Nintedanib in Subgroups of 
Idiopathic Pulmonary Fibrosis by Diagnostic Criteria. Am J Respir Crit Care Med 2017; 195:78-85.

7. Panel on Handling Missing Data in Clinical Trials, National Research Council. The Prevention and Treatment of Missing Data in Clinical Trials. Washington, DC: National Academies Press; 2010.

8. Noble PW, Albera C, Bradford WZ, Costabel U, Glassberg MK, Kadatzke D, King TE, lancaster L, Sahn SA, Szwarcberg J, Valeyre D, Bois du RM, Group FTCS. Pirfenidone in patients with idiopathic pulmonary fibrosis (CAPACITY): two randomised trials. Lancet 2011;377:1760-1769.

9. Wuyts WA, Antoniou KM, Borensztajn K, Costabel U, Cottin V, Crestani B, Grutters JC, Maher TM, Poletti V, Richeldi L, Vancheri C, Wells AU. Combination therapy: the future of management for idiopathic pulmonary fibrosis? Lancet Respir Med 2014;2:933-942.

10. Collard HR, Bradford WZ, Cottin V, Flaherty KR, King ET, Koch GG, Kolb M, Martinez FJ, Montgomery B, Raghu G, Richeldi L, Rose D, Wells AU, Brown KK. A new era in idiopathic pulmonary fibrosis: considerations for future clinical trials. Eur Respir J 2015;46:243-9. 